\title{
Micropropagação de sucupira-preta por meio de gemas axilares
}

\author{
Luciana Coelho de Moura(1), Miranda Titon ${ }^{(1)}$, José Sebastião Cunha Fernandes ${ }^{(2)}$, Reynaldo Campos Santana(1) \\ e Marcio Leles Romarco de Oliveira(1)
}

(1)Universidade Federal dos Vales do Jequitinhonha e Mucuri (UFVJM), Departamento de Engenharia Florestal, Rodovia MGT-367, Km 583, no 5.000, Alto da Jacuba, CEP 39100-000 Diamantina, MG. E-mail: lucianacm2005@yahoo.com.br, mirandatiton@gmail.com, silviculturaufvjm@yahoo.com.br, marcioromarco@gmail.com (2)UFVJM, Departamento de Agronomia. E-mail: cunha.fernandes@yahoo.com.br

Resumo - O objetivo deste trabalho foi avaliar o uso de reguladores de crescimento, aditivos antioxidantes, tipo de explantes e intensidade de cobertura de mudas aclimatizadas, na micropropagação de sucupira-preta (Bowdichia virgilioides) por meio de gemas axilares. Os explantes foram cultivados para a multiplicação em meio de cultura básico WPM, suplementado com concentrações de benzilaminopurina (BAP). No alongamento, os tratamentos foram combinações de ácido naftalenoacético (ANA) e BAP adicionadas ao meio. Para o enraizamento, as brotações foram colocadas em meio com concentrações de ácido indolbutírico, ou em meio com combinações dos aditivos polivinilpirrolidona e carvão ativado, em diferentes concentrações de ANA. As plantas foram transplantadas para copos de plástico, com substrato, e cobertas com saco de polietileno. Posteriormente, esses sacos foram retirados, ou perfurados, ou não retirados, o que constituiu os tratamentos de pré-aclimatização in vitro. A aclimatização ex vitro foi realizada após o período de pré-aclimatização in vitro. A sucupira-preta apresentou melhor micropropagação com emprego de: segmentos cotiledonares e $0,3 \mathrm{mg} \mathrm{L}^{-1}$ de BAP, na multiplicação; $0,3 \mathrm{mg} \mathrm{L}^{-1}$ de ANA e $0,03 \mathrm{mg} \mathrm{L}^{-1}$ de BAP, no alongamento; e carvão ativado $\left(2,0 \mathrm{mg} \mathrm{L}^{-1}\right)$, no enraizamento e na pré-aclimatização in vitro, com uso de cobertura de plástico transparente em torno da muda.

Termos para indexação: Bowdichia virgilioides, cultura de tecidos, espécie nativa, propagação, reguladores de crescimento.

\section{Sucupira-preta micropropagation through axillary buds}

Abstract - The objective of this work was to evaluate the use of growth regulators, antioxidant additives, type of explants, and coverage intensity of acclimatized seedlings in the micropropagation of sucupira-preta (Bowdichia virgilioides) through axillary buds. Explants were cultured for multiplication on WPM medium, supplemented with concentrations of benzylaminopurine (BAP). In the elongation phase, treatments consisted of naphthaleneacetic acid (NAA) and BAP combinations added to the medium. For rooting, shoots were inoculated in medium containing concentrations of indolbutyric acid or combinations of the additives polyvinylpyrrolidone and charcoal, in different NAA concentrations. Plants were transplanted to plastic cups with substrate, and covered with polyethylene bags. Later, the bags were withdrawn, or perforated, or not withdrawn, which constituted the in vitro pre-acclimatization treatments. Ex vitro acclimatization was carried out after the period of in vitro pre-acclimatization. Sucupira-preta had the best micropropagation using: cotyledon segments and $0.3 \mathrm{mg} \mathrm{L}^{-1} \mathrm{BAP}$, for multiplication; $0.3 \mathrm{mg} \mathrm{L}^{-1} \mathrm{NAA}$ and $0.03 \mathrm{mg} \mathrm{L}^{-1} \mathrm{BAP}$, for elongation; and 2,0 $\mathrm{mg} \mathrm{L}^{-1}$ activated carbon for rooting and for the in vitro pre-acclimatization, with the use of a transparent plastic cover around seedling.

Index terms: Bowdichia virgilioides, tissue culture, native species, propagation, growth regulators.

\section{Introdução}

A sucupira-preta (Bowdichia virgilioides Kunth.) é uma espécie da família Fabaceae com madeira densa, de cerne pardo escuro, de alta durabilidade, utilizada em móveis de luxo, acabamentos internos, construções, dormentes e pontes, entre outros usos. Sua propagação é realizada principalmente com sementes. Entretanto, em decorrência da dormência tegumentar, estas têm baixa taxa de germinação: entre 0 e $2 \%$, sem a superação da dormência, e entre 45 e $88 \%$, com a superação da dormência (Carvalho, 2006). Portanto, a micropropagação representa uma alternativa para a produção de mudas desta espécie.

A micropropagação é recomendada para espécies que têm dificuldade de germinação e armazenamento, e permite maximizar a qualidade e uniformidade dos plantios, quando são utilizados genótipos selecionados. 
No entanto, o uso prático dessa técnica exige a otimização das condições de cultivo para cada espécie. Entre os fatores que mais contribuem para o sucesso da micropropagação estão os reguladores de crescimento, em especial as citocininas e as auxinas (Rogalski, 2003). A formação de raízes, parte aérea e calos, e a proliferação de gemas, são regulados pela presença e interação dessas duas classes de reguladores (Caldas et al., 1999).

Entre as citocininas comercialmente disponíveis, a 6-benzilaminopurina (BAP) é a que, em geral, apresenta melhores resultados. As auxinas mais utilizadas são o ácido naftalenoacético (ANA), na fase de alongamento, e o ácido indolbutírico (AIB), na indução de raízes in vitro (Grattapaglia \& Machado, 1999).

A aclimatização e rustificação em condições ex vitro é uma etapa importante na formação de mudas microprogadas in vitro, uma vez que esse material passa de uma condição heterotrófica para a autotrófica, o que causa estresses fisiológicos (Bandeira et al., 2007). Em razão do estresse causado pela diferença entre os ambientes in vitro e ex vitro, durante a aclimatização ocorrem grandes perdas de explantes (Dutra et al., 2009). Dessa forma, o sucesso de um sistema de micropropagação depende do controle de grande número de variáveis, em cada uma de suas fases.

O objetivo deste trabalho foi avaliar o efeito do uso de reguladores de crescimento, aditivos antioxidantes, tipo de explantes e intensidade de cobertura de mudas aclimatizadas, na micropropagação de sucupira-preta por meio de gemas axilares.

\section{Material e Métodos}

Os experimentos foram realizados no Laboratório de Melhoramento Florestal e na casa de vegetação (coberta com filme de plástico com $150 \mu$ de espessura e com tela de 50\% sombreamento) da Universidade Federal dos Vales do Jequitinhonha e Mucuri, Diamantina, MG, de setembro de 2010 a novembro de 2011.

Frutos de sucupira-preta foram coletados de matrizes localizadas no Parque Estadual do Rio Preto, no Município de São Gonçalo do Rio Preto, MG. Após a retirada manual das sementes dos frutos, as sementes viáveis foram armazenadas em sacos de papel, no laboratório, à temperatura ambiente.

Para a germinação in vitro, sementes com sete meses de armazenamento foram escarificadas com lixa d'água ํo 20 e desinfestadas com hipoclorito de sódio a 2,5\% (v/v) por $15 \mathrm{~min}$. Foram utilizados tubos de ensaio $(25 \times 150 \mathrm{~mm})$, vedados com duas camadas de insulfilm transparente, com $10 \mathrm{~mL}$ de meio de cultura constituído de sais e vitaminas de MS (Murashige \& Skoog, 1962), $100 \mathrm{mg} \mathrm{L}^{-1}$ de mioinositol, $20 \mathrm{~g} \mathrm{~L}^{-1} \mathrm{de}$ sacarose e $5 \mathrm{~g} \mathrm{~L}^{-1}$ de ágar Merck. $\mathrm{O} \mathrm{pH}$ do meio de cultura foi ajustado para $5,8 \pm 0,01$ e foi autoclavado por $15 \mathrm{~min}$, a $121^{\circ} \mathrm{C}$ e pressão de $1 \mathrm{~atm}$. Foi implantada uma semente por frasco. Em seguida, os frascos foram vedados e mantidos em sala de cultura, com fotoperíodo de 16 horas de luz e 8 horas de escuro, irradiância de $30 \mu \mathrm{mol} \mathrm{m} \mathrm{m}^{-2} \mathrm{~s}^{-1}$ e temperatura de $25 \pm 2^{\circ} \mathrm{C}$, até a germinação.

A multiplicação dos explantes foi realizada com um cultivo inicial e três cultivos subsequentes (cultivos 1,2 e 3). Definiu-se como cultivo inicial o primeiro cultivo de multiplicação realizado após a germinação das plântulas. Para esse cultivo, os dois tipos de explantes utilizados - segmentos cotiledonares e segmentos nodais, com tamanho aproximado de $1 \mathrm{~cm}$ - foram retirados de plântulas germinadas in vitro, isentas de contaminações, com aproximadamente 30 dias de idade. Para os cultivos subsequentes (cultivos 1, 2 e 3), utilizaram-se explantes retirados do cultivo imediatamente anterior, com tamanho aproximado de $1 \mathrm{~cm}$, isentos de contaminações e com aproximadamente 30 dias de idade. Para avaliar o efeito do tipo de explante (segmentos cotiledonares ou segmentos nodais), respeitou-se o histórico do explante, ou seja: no cultivo 1, utilizaram-se gemas axilares, retiradas de segmentos nodais e de segmentos cotiledonares do cultivo inicial; no cultivo 2, utilizaram-se gemas axilares, retiradas de segmentos nodais e de segmentos cotiledonares do cultivo 1, e assim sucessivamente.

Para o cultivo inicial e os subsequentes, os explantes foram implantados verticalmente em tubos de ensaio, vedados com tampa de polietileno, com $10 \mathrm{~mL}$ de meio de cultura básico previamente preparado e autoclavado. Utilizou-se o meio de cultura básico WPM (Lloyd \& McCown, 1981), com 100\% da concentração dos sais e vitaminas, suplementado com $100 \mathrm{mg} \mathrm{L}^{-1}$ de mioinositol, $800 \mathrm{mg} \mathrm{L}^{-1}$ de polivinilpirrolidona (PVP), $20 \mathrm{~g} \mathrm{~L}^{-1}$ de sacarose, $0,01 \mathrm{mg} \mathrm{L}^{-1}$ de ANA e BAP nas concentrações 0,1 e $0,3 \mathrm{mg} \mathrm{L}^{-1}$, com $\mathrm{pH}$ ajustado para $5,8 \pm 0,01$, antes da inclusão de $5 \mathrm{~g} \mathrm{~L}^{-1}$ de ágar Merck. Utilizou-se o delineamento experimental inteiramente ao acaso, em arranjo fatorial $2 \times 2$ (dois tipos de explantes 
e duas concentrações de BAP), com quatro repetições e seis explantes por repetição.

Os experimentos foram realizados em sala de cultura com fotoperíodo de 16 horas de luz e 8 horas de escuro, irradiância de $30 \mu \mathrm{mol} \mathrm{m} \mathrm{m}^{-2} \mathrm{~s}^{-1} \mathrm{e}$ temperatura de $25 \pm 2^{\circ} \mathrm{C}$. Na multiplicação, avaliou-se o número de gemas axilares por explante aos 30 dias, para o cultivo inicial, e aos 40 dias para os três cultivos subsequentes. Os dados foram submetidos à análise de variância e testes de média, com o programa Statistica 10.0 (Statsoft, 2010).

$\mathrm{O}$ alongamento das gemas axilares foi realizado com as obtidas na fase de multiplicação, aos 40 dias, em meio de cultura com $0,3 \mathrm{mg} \mathrm{L}^{-1}$ de BAP e $0,01 \mathrm{mg} \mathrm{L}^{-1}$ de ANA. Os explantes foram colocados verticalmente em tubos de ensaio, vedados com tampa de polietileno, com $10 \mathrm{~mL}$ de meio de cultura básico previamente preparado e autoclavado. Utilizou-se o meio de cultura básico WPM (Lloyd \&McCown, 1981), com 100\% da concentração dos sais e vitaminas, suplementado com $100 \mathrm{mg} \mathrm{L}^{-1}$ de mioinositol, $800 \mathrm{mg} \mathrm{L}^{-1}$ de PVP, $20 \mathrm{~g} \mathrm{~L}^{-1}$ de sacarose. $\mathrm{O} \mathrm{pH}$ foi ajustado para $5,8 \pm 0,01$, antes da inclusão de $5 \mathrm{~g} \mathrm{~L}^{-1}$ de ágar Merck e da adição dos reguladores de crescimento nas concentrações 0,1 , 0,3 e $0,6 \mathrm{mg} \mathrm{L}^{-1}$ de ANA, com 0,01, 0,03 e $0,06 \mathrm{mg} \mathrm{L}^{-1}$ de BAP. A adição dos reguladores de crescimento foi realizada após o preparo do meio de cultura básico e antes da autoclavagem. $\mathrm{O}$ delineamento experimental inteiramente ao acaso foi utilizado em arranjo fatorial 3x3 (três concentrações de BAP e três concentrações de ANA), com cinco repetições e quatro explantes por repetição. Considerou-se, como parcela, cada frasco de cultivo $(55 \times 90 \mathrm{~mm})$, com quatro gemas axilares em $40 \mathrm{~mL}$ de meio de cultura. Os frascos com os explantes foram mantidos, durante 40 dias em sala de cultura com fotoperíodo de 16 horas de luz e 8 horas de escuro, irradiância de $30 \mu \mathrm{mol} \mathrm{m}^{-2} \mathrm{~s}^{-1}$ e temperatura de $25 \pm 2^{\circ} \mathrm{C}$. Aos 40 dias de alongamento, avaliou-se o comprimento da maior brotação $(\mathrm{cm})$. Os dados foram submetidos à análise de variância e a testes de média, com o auxílio do programa Statistica 10.0 (Statsoft, 2010).

$\mathrm{Na}$ fase de enraizamento in vitro, foram realizados dois ensaios. No primeiro, as brotações foram retiradas de plantas multiplicadas em meio de cultura com 0,3 $\mathrm{mg} \mathrm{L}^{-1}$ de BAP e $0,01 \mathrm{mg} \mathrm{L}^{-1}$ de ANA, com 90 dias. No segundo ensaio, utilizaram-se brotações retiradas de plantas alongadas em meio com $0,3 \mathrm{mg} \mathrm{L}^{-1}$ de ANA e $0,03 \mathrm{mg} \mathrm{L}^{-1}$ de BAP, com 40 dias. As brotações utilizadas na fase de enraizamento tinham altura aproximada de $2 \mathrm{~cm}$.

No primeiro ensaio de enraizamento, as brotações foram submetidas ao tratamento com concentrações de $0,0,5,1,0,1,5,2,0,2,5,3,0,3,5$ e $4,0 \mathrm{mg} \mathrm{L}^{-1}$ de AIB, adicionadas ao meio de cultura antes da autoclavagem. Para minimizar a oxidação da base das brotações, $800 \mathrm{mg} \mathrm{L}^{-1}$ de PVP foram adicionados ao meio básico. Foi utilizado o delineamento experimental inteiramente ao acaso com quatro repetições e seis brotações por repetição. No segundo ensaio, as brotações foram submetidas ao tratamento de combinações de dois tipos de aditivos: carvão ativado e PVP, nas concentrações de 2.000 e de $800 \mathrm{mg} \mathrm{L}^{-1}$, respectivamente, com quatro concentrações de ANA $(0$, 1,2 e $4 \mathrm{mg} \mathrm{L}^{-1}$ ), adicionadas ao meio de cultura antes da autoclavagem. A adição do carvão ativado foi realizada após o ajuste do $\mathrm{pH}$. Utilizou-se o delineamento experimental inteiramente ao acaso em arranjo fatorial $2 \times 4$ (dois aditivos e quatro concentrações de ANA), com quatro repetições e seis brotações por repetição.

O carvão ativado é um dos compostos mais utilizados para induzir a rizogênese in vitro, por auxiliar na adsorção de substâncias tóxicas em excesso no meio de cultura, como fenóis e reguladores de crescimento. Além disso, proporciona redução na incidência de luz na zona de crescimento ativo do sistema radicular, o que estimula a formação de raízes (Bonga, 1985).

Nos dois ensaios, as brotações foram colocadas verticalmente, nos tubos de ensaio vedados com tampa de polietileno, que continham $10 \mathrm{~mL}$ de meio de cultura básico previamente preparado e autoclavado. Utilizouse o meio de cultura básico WPM (Lloyd \& McCown, 1981), com $100 \%$ da concentração dos sais e vitaminas, suplementado com $100 \mathrm{mg} \mathrm{L}^{-1}$ de mioinositol, $20 \mathrm{~g} \mathrm{~L}^{-1}$ de sacarose, com pH ajustado para 5,8 80,01 , antes da inclusão de $5 \mathrm{~g} \mathrm{~L}^{-1}$ de ágar Merck. Os tubos de ensaio com as brotações foram mantidos em sala de cultura, com fotoperíodo de 16 horas de luz e 8 horas de escuro, irradiância de $30 \mu \mathrm{mol} \mathrm{m} \mathrm{m}^{-2} \mathrm{~s}^{-1} \mathrm{e}$ temperatura de $25 \pm 2^{\circ} \mathrm{C}$, durante 120 dias.

Aos 60 e aos 120 dias, avaliaram-se os percentuais de enraizamento e calosidade das brotações submetidas ao AIB. Aos 120 dias, avaliaram-se: percentual de enraizamento e de calosidade das brotações, percentual de clorose, de queda de folhas e de plantas bem desenvolvidas, das brotações submetidas aos aditivos e concentrações de ANA. Os dados obtidos foram 
submetidos à análise de variância, aos testes de média e à análise de regressão, com o auxílio do programa Statistica 10.0 (Statsoft, 2010).

Para a pré-aclimatação in vitro, plantas maiores que $2 \mathrm{~cm}$ de comprimento - enraizadas in vitro e com 120 dias - foram transplantadas para copos de polietileno de $200 \mathrm{~cm}^{3}$, que continham substrato composto por $70 \%$ de vermiculita e $30 \%$ de Bioplant. As plantas foram cobertas com saco de polietileno transparente e mantidas em laboratório, sem nenhum controle das condições ambientais. Foram realizadas irrigações de dois em dois dias, com solução de macro e micronutrientes WPM a $50 \%$ da concentração dos sais e vitaminas. Após 10 dias de pré-aclimatização in vitro, foram aplicados os tratamentos: T1, retirada total dos sacos de polietileno; T2, abertura parcial nos sacos de polietileno (seis furos, três de cada lado); e T3, permanência do saco de polietileno intacto. Utilizou-se o delineamento inteiramente ao acaso, com oito repetições. Após 60 dias de pré-aclimatização in vitro, as plantas foram transplantadas para tubetes de $180 \mathrm{~cm}^{3}$, que continham substrato composto por $70 \%$ de vermiculita e $30 \%$ de Bioplant, adicionado de $7 \mathrm{~g} \mathrm{~L}^{-1}$ do adubo formulado de liberação controlada (3 a 4 meses) Osmocote (19-6-10). A casa de vegetação onde os tubetes foram mantidos era coberta com filme de plástico ( $150 \mu$ de espessura) e com tela de $50 \%$ de sombreamento, submetida a três irrigações diárias de 3 min cada por nebulização (nebulizador Fogger, com vazão de 7 L por hora). Para o processo de aclimatização ex vitro, os tubetes foram mantidos durante mais 30 dias. Durante esse processo, manteve-se o histórico dos tratamentos da aclimatização in vitro (T1, T2 e T3). Utilizou-se o delineamento inteiramente ao acaso, com oito repetições. Os valores de temperatura e umidade relativa do ar na casa de vegetação foram registrados diariamente.

Aos 60 dias de pré-aclimatização in vitro, avaliaramse a sobrevivência, altura, número de raízes e o aspecto visual da parte aérea, que foi classificado numa escala de 1 a 4, em que 1 representa baixo vigor e 4 representa vigor ótimo. Aos 30 dias de aclimatização ex vitro, avaliaram-se o percentual de sobrevivência e a altura das mudas. Os dados foram submetidos à análise de variância, aos testes de médias e às análises descritivas, com o auxílio do programa Statistica 10.0 (Statsoft, 2010).
Quando os dados dos experimentos não apresentaram distribuição normal, pelo teste Lilliefors, a $5 \%$ de probabilidade, seus valores foram transformados para $\mathrm{x}^{0,5}$.

\section{Resultados e Discussão}

$\mathrm{Na}$ fase de multiplicação, ocorreram os seguintes efeitos significativos $(\mathrm{p}<0,05)$ quanto ao número médio de gemas por explante: interação tipo de explante e concentrações de BAP (E x B), no cultivo 1; tipo de explante, no cultivo inicial e no cultivo 3; e concentrações de BAP, no cultivo 2.

No desdobramento da interação $\mathrm{E}$ x $\mathrm{B}$, o número de gemas axilares obtido por explante de segmento nodal foi superior ao obtido por explante de segmento cotiledonar, à concentração $0,3 \mathrm{mg} \mathrm{L}^{-1}$ de BAP, no cultivo 1 (Tabela 1). Ao se analisar separadamente o segmento nodal, no cultivo 1, observa-se que a concentração $0,3 \mathrm{mg} \mathrm{L}^{-1}$ proporcionou melhores resultados que a de $0,1 \mathrm{mg} \mathrm{L}^{-1}$ de BAP.

Quanto ao efeito do explante, analisado isoladamente, no cultivo inicial e no cultivo 3, o segmento cotiledonar foi superior ao segmento nodal (Figura 1). Este resultado pode ser explicado pelo fato de se tratar de material juvenil, em que o balanço hormonal interno é favorável à proliferação celular (Xavier et al., 2003). Costa et al. (2010) observaram que o segmento cotiledonar tem maior capacidade de regeneração que o segmento nodal, em explantes de mulungu (Erythrina velutina Willd).

Quanto ao efeito isolado das concentrações de BAP, no cultivo 2 , a concentração de $0,3 \mathrm{mg} \mathrm{L}^{-1}$ proporcionou novamente resultados superiores à concentração de

Tabela 1. Efeitos principais do tipo de explante (Cotiledonar ou Nodal) e da concentração utilizada de BAP $(0,1$ ou $0,3 \mathrm{mg} \mathrm{L}^{-1}$ ), bem como efeito da interação entre os fatores (Cultivo 1), no número médio de gemas axilares por explante de sucupira-preta ${ }^{(1)}$.

\begin{tabular}{lccccc}
\hline Fator de & Cultivo & \multicolumn{2}{c}{ Cultivo 1 } & Cultivo 2 & Cultivo 3 \\
\cline { 3 - 4 } variação & inicial & $0,1 \mathrm{mg} \mathrm{L}^{-1}$ & $0,3 \mathrm{mg} \mathrm{L}^{-1}$ & & \\
\hline Cotiledonar & $11,30 \mathrm{~A}$ & $3,38 \mathrm{Aa}$ & $2,50 \mathrm{Ba}$ & - & $15,06 \mathrm{~A}$ \\
Nodal & $7,65 \mathrm{~B}$ & $2,09 \mathrm{Ab}$ & $7,29 \mathrm{Aa}$ & - & $10,55 \mathrm{~B}$ \\
$0,1 \mathrm{mg} \mathrm{L}$ & -1 & - & - & $3,88 \mathrm{~B}$ & - \\
$0,3 \mathrm{mg} \mathrm{L}^{-1}$ & - & - & - & $6,07 \mathrm{~A}$ & - \\
\hline
\end{tabular}

${ }^{(1)}$ Médias seguidas por letras iguais, maiúsculas nas colunas e minúsculas nas linhas, não diferem entre si, pelo teste de Tukey, a 5\% de probabilidade. 
0,1 mg L $\mathrm{me}^{-1}$ de BAP. As citocininas são uma classe de reguladores com capacidade marcante de induzir a divisão celular em tecidos vegetais. Portanto, elas são importantes para a formação de órgãos, principalmente os aéreos. A benzilaminopurina (BAP) é uma citocinina sintética, utilizada para a multiplicação in vitro de diversas espécies (Lucas et al., 2007). Ribas et al. (2005) utilizaram segmentos nodais de peroba-rosa (Aspidosperma polyneuron Müll. Arg.) e BAP, adicionado ao meio de cultura $\left(1,0\right.$ a $\left.2,0 \mathrm{mg} \mathrm{L}^{-1}\right)$, e obtiveram 4,0 a 5,0 brotações por explante. Cordeiro et al. (2004) observaram 2, 0 a 3,0 brotos produzidos por explante de paricá [Schizolobium amazonicum Huber (Duck)] à medida que foi aumentada a concentração de BAP, até $2,5 \mathrm{mg} \mathrm{L}^{-1}$.

$\mathrm{Na}$ fase de alongamento, não foram encontradas diferenças significativas $(\mathrm{p}>0,05)$ entre os tratamentos, quanto à altura média dos explantes, aos 40 dias. No entanto, a concentração de $0,3 \mathrm{mg} \mathrm{L}^{-1}$ de ANA, combinada com as três concentrações de BAP, em especial a de $0,03 \mathrm{mg} \mathrm{L}^{-1}$, apresentou valores numericamente superiores de altura média do explante $(2,54 \mathrm{~cm})$. A partir de $0,3 \mathrm{mg} \mathrm{L}^{-1}$ de ANA, observouse decréscimo na altura das plantas com as três concentrações de BAP, em média 1,72 cm (Figura 2). Isso pode estar ligado ao fato de que as citocininas estimulam maior produção da parte aérea até uma determinada concentração, o que varia de acordo com a espécie, e pode ocorrer, em certas condições, resposta negativa ao aumento na concentração hormonal (Xavier et al., 2003).

$\mathrm{Na}$ fase de enraizamento, foram encontradas diferenças significativas $(\mathrm{p}<0,05)$ entre os tratamentos,

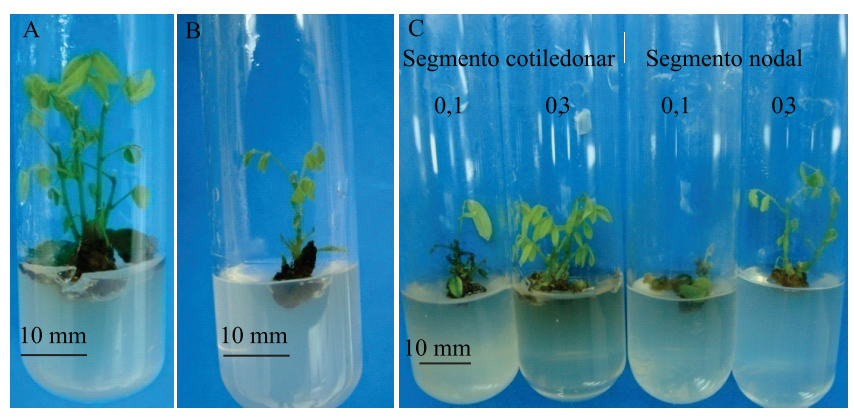

Figura 1. Multiplicação in vitro de explantes de sucupira-preta. Cultivo inicial: A, segmento cotiledonar, e $\mathrm{B}$, segmento nodal. Cultivo 2: C, segmentos cotiledonar e nodal, combinados com as concentrações de 0,1 e $0,3 \mathrm{mg}$ $\mathrm{L}^{-1}$ de BAP. quanto ao percentual de calosidade, aos 60 dias. Observou-se tendência crescente no percentual de calosidade, à medida que foi aumentada concentração de AIB (Figura 3 A). A formação de calos na base do explante pode ser indício de enraizamento futuro pois, em espécies de difícil enraizamento, geralmente há formação de calos que precedem a formação de raízes (Hamann, 1998). Isso pode ser comprovado pelo aumento do percentual de enraizamento médio: de 2,31\%, aos 60 dias, para 20,83\%, aos 120 dias. Quanto ao enraizamento aos 120 dias, as concentrações de 2,5, 0,0 e $0,5 \mathrm{mg} \mathrm{L}^{-1}$ de AIB foram as que proporcionaram os maiores percentuais: 31,7 , 29,2 e $29,2 \%$, respectivamente (Figura 3 B). Couto et al. (2003) também obtiveram maiores percentuais de enraizamento de porta-enxertos de pessegueiro (Prunus sp. Barrier), com essas mesmas concentrações de AIB adicionadas ao meio de cultura. Rocha et al. (2007) estudaram Cabralea canjerana (Vell) Mart. e observaram que o comprimento médio de raízes foi superior nos tratamentos com $0,5 \mathrm{mg} \mathrm{L}^{-1}$ de AIB, em comparação às demais concentrações testadas de auxinas.

O percentual de enraizamento aos 120 dias foi bastante irregular, o que pode ser explicado pelo fato de o crescimento de raízes ser controlado geneticamente e pela herança de caracteres quantitativos (Camargo \& Ferreira Filho, 2005). Aos 120 dias, foram encontrados efeitos significativos $(p<0,05)$ da interação entre os fatores (aditivos x ANA) e dos efeitos principais de aditivos e de concentração de ANA, para o percentual de explantes com clorose foliar.

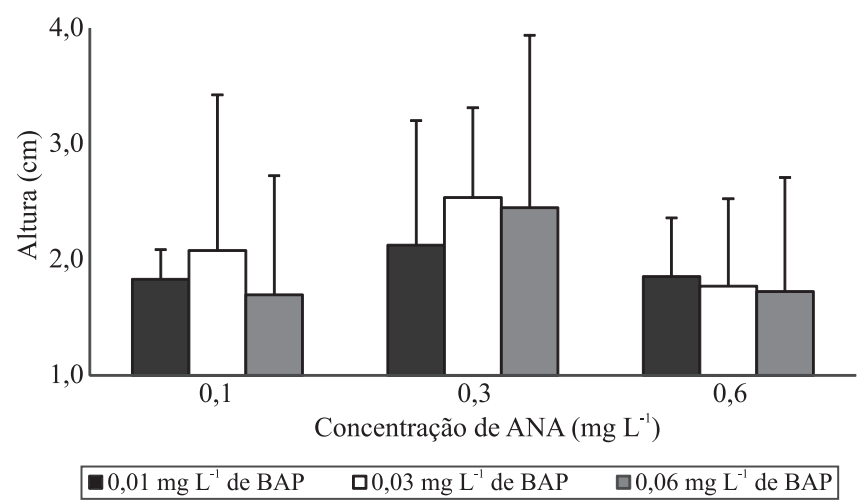

Figura 2. Altura média de explantes de sucupira-preta, em razão das concentrações de ANA e BAP, aos 40 dias de alongamento. As barras indicam o desvio-padrão. 
O carvão ativado proporcionou menor percentual de clorose foliar, em comparação ao PVP, em todas as concentrações estudadas de ANA (Tabela 2). Disarz \& Corder (2009), que trabalharam com micropropagação de acácia (Acacia mearnsii De Wild.), não observaram clorose em explantes cultivados subsequentemente em meio MS com a adição de carvão ativado. Segundo Gomes et al. (2010), o carvão ativado combinado com o AIB promove a formação de raízes em explantes de Maclura tinctoria Lumber, por reduzir a ação oxidante.

Durante a permanência das mudas na casa de vegetação, a temperatura média foi de $19,1^{\circ} \mathrm{C}$, e a umidade média foi de 81,6\%. Aos 60 dias da pré-aclimatização in vitro, observou-se $100 \%$ de sobrevivência, em todos os tratamentos e, aos 30 dias de aclimatização ex vitro, observou-se 0,50 e $75 \%$ de sobrevivência nos tratamentos T1, T2 e T3, respectivamente. Foram observadas diferenças significativas $(p<0,05)$ entre os tratamentos, quanto ao número de raízes, na fase de pré-aclimatização in vitro, e quanto à altura, na fase de aclimatização ex vitro.
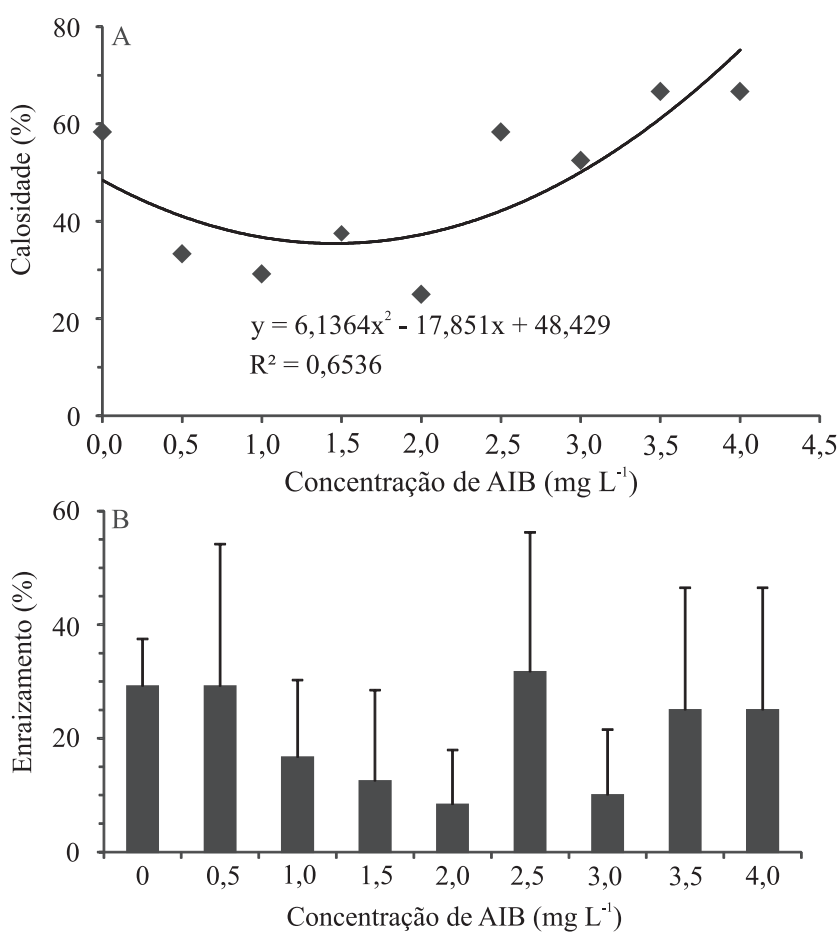

Figura 3. Percentual de calosidade em brotações de sucupira-preta, aos 60 dias (A) e percentual de enraizamento aos 120 dias (B), em razão das concentrações de AIB. As barras indicam o desvio-padrão.
O tratamento T3 (permanência do saco de polietileno) foi estatisticamente superior ao $\mathrm{T} 1$ (ausência de saco de polietileno), quanto ao número de raízes durante a pré-aclimatização in vitro, e quanto à altura durante a aclimatização ex vitro (Tabela 3 ). Tratamentos de redução gradativa de umidade relativa são recomendados para aumentar a sobrevivência no transplantio, já que resultam em uma adaptação mais rápida dos estômatos do que em plantas transplantadas diretamente para a casa de vegetação (Grattapaglia \& Machado, 1999). Augusto et al. (2006) observaram que o uso de túnel de plástico, na aclimatização ex vitro de plantas de amoreira-preta enraizadas in vitro, leva ao maior crescimento das plantas.

Com relação ao vigor da parte aérea de plantas pré-aclimatadas, aos 60 dias, observa-se que o tratamento T3 (permanência do saco de polietileno) foi superior ao T2 (saco de polietileno perfurado) que, por sua vez, foi superior ao T1 (ausência de saco de polietileno) (Figura 4). Este fato deve ser atribuído, em grande parte, à mudança nas condições ambientais às quais as plântulas foram submetidas, principalmente a umidade relativa, que era maior no interior do saco de plástico, mais próxima daquela encontrada no interior do tubo de ensaio (Nicioli et al., 2008).

Tabela 2. Percentual de calosidade e de clorose foliar, em razão dos aditivos e das concentrações de ANA $(0,0,1,0$, 2,0 e 4,0 $\left.\mathrm{mg} \mathrm{L}^{-1}\right)$, em brotações de sucupira-preta, aos 120 $\operatorname{dias}^{(1)}$.

\begin{tabular}{lccccc}
\hline Aditivo & Calosidade & \multicolumn{4}{c}{ Clorose foliar (\%) } \\
\cline { 3 - 6 } & $(\%)$ & 0,0 & 1,0 & 2,0 & 4,0 \\
\hline Carvão ativado & $15,0 \mathrm{~B}$ & $45,0 \mathrm{Bb}$ & $80,0 \mathrm{Ba}$ & $60,0 \mathrm{Bab}$ & $65,0 \mathrm{Bab}$ \\
PVP & $42,5 \mathrm{~A}$ & $90,0 \mathrm{Aa}$ & $85,0 \mathrm{Aa}$ & $100,0 \mathrm{Aa}$ & $95,0 \mathrm{Aa}$ \\
\hline
\end{tabular}

${ }^{(1)}$ Médias seguidas por letras iguais, maiúsculas nas colunas e minúsculas nas linhas, não diferem entre si, pelo teste de Tukey, a $5 \%$ de probabilidade.

Tabela 3. Número de raízes, aos 60 dias de pré-aclimatização in vitro, e altura de plantas, aos 30 dias de aclimatização ex vitro, de sucupira-preta em casa de vegetação, em razão dos tratamentos pré-aclimatização in vitro sem o uso de sacos de polietileno (T1) ou com o uso de sacos perfurados (T2) ou intactos $(\mathrm{T} 3)^{(1)}$.

\begin{tabular}{lcc}
\hline Tratamento & Número de raízes & Altura $(\mathrm{cm})$ \\
\hline T1 & $0,63 \mathrm{~B}$ & $0,00 \mathrm{~B}$ \\
$\mathrm{~T} 2$ & $1,50 \mathrm{AB}$ & $1,70 \mathrm{AB}$ \\
$\mathrm{T} 3$ & $2,38 \mathrm{~A}$ & $1,96 \mathrm{~A}$ \\
\hline
\end{tabular}

(1)Médias seguidas por letras iguais não diferem entre si, pelo teste de Tukey, a $5 \%$ de probabilidade. 


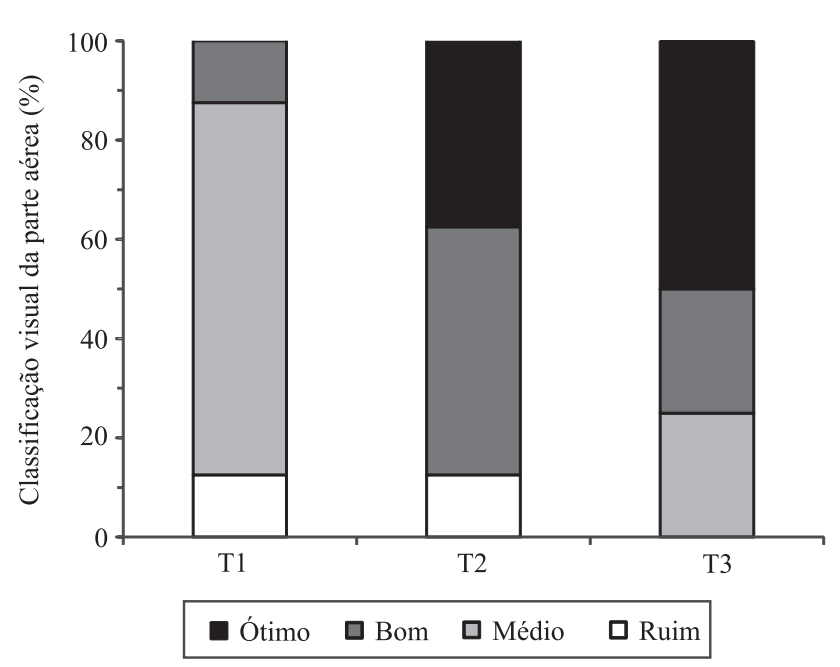

Figura 4. Classificação do vigor da parte aérea de mudas de sucupira-preta, na fase de aclimatização, aos 60 dias, em razão dos tratamentos: $\mathrm{T} 1$, retirada total dos sacos de polietileno; T2, aberturas parciais nos sacos de polietileno; e T3, permanência do saco de polietileno intacto.

\section{Conclusões}

1. O uso de segmentos cotiledonares e a adição de $0,3 \mathrm{mg} \mathrm{\textrm {L } ^ { - 1 }}$ de BAP ao meio de cultura favorecem a emissão de gemas axilares de explantes de sucupira-preta.

2. O alongamento dos explantes é favorecido pelo uso de $0,3 \mathrm{mg} \mathrm{L}^{-1}$ de ANA e de $0,03 \mathrm{mg} \mathrm{L}^{-1}$ de BAP, adicionados ao meio de cultura.

3. Reguladores de crescimento não aumentam o percentual de enraizamento da sucupira-preta; porém, o uso do carvão ativado no meio de cultura, durante o enraizamento, aumenta a qualidade das brotações.

4. O uso de cobertura de plástico transparente, em torno das mudas, favorece a pré-aclimatização in vitro das plantas.

\section{Agradecimentos}

À Universidade Federal dos Vales do Jequitinhonha e Mucuri, ao Programa Nacional de Cooperação Acadêmica da Coordenação de Aperfeiçoamento de Pessoal de Nível Superior (Capes), à Fundação de Amparo à Pesquisa do Estado de Minas Gerais (Fapemig), ao Instituto Estadual de Florestas e à Secretaria de Estado de Ciência, Tecnologia e Ensino Superior, pelo apoio financeiro.

\section{Referências}

AUGUSTO, C.S.S.; BIASI, L.A.; TELLES C.A. Enraizamento e aclimatação de plantas micropropagadas de amoreira-preta cv. Brazos. Revista Brasileira de Fruticultura, v.28, p.473-476, 2006.

BANDEIRA, F.S.; XAVIER, A.; OTONI, W.C.; LANI, E.R.G. Aclimatização ex vitro de plantas propagadas pela enxertia in vitro de Eucalyptus urophylla x E. grandis. Revista Árvore, v.3, p.773-781, 2007.

BONGA, J.M. Tissue culture techniques. In: BONGA, J.M.; DURZAN, D.J. Tissue culture in forestry. Dordrecht: Martinus Nijhoff, 1985. p.4-35.

CALDAS, L.S.; HARIDASAN, P.; FERREIRA, M.E. Meios nutritivos. In: TORRES, A.C.; CALDAS, L.S.; BUSO, J.A. (Ed.). Cultura de tecidos e transformação genética de plantas. Brasília: Embrapa-SPI: Embrapa-CNPH, 1999. v.2, p.87-132.

CAMARGO, C.E.O.; FERREIRA FILHO A.W.P. Genetic control of wheat seedling root growth. Scientia Agricola, v.62, p.325-330, 2005.

CARVALHO, P.E.R. Espécies arbóreas brasileiras. Brasília: Embrapa Informação Tecnológica; Colombo: Embrapa Florestas, 2006. v.2, 627p.

CORDEIRO, I.M.C.C.; LAMEIRA, O.A.; OHASHI, S.T.; ROSAL, L.F. Efeito de BAP sobre a proliferação de brotos in vitro de Schizolobium amazonicum Huber ex Ducke (paricá). Cerne, v.10, p.118-124, 2004.

COSTA, G.M. da; NEPOMUCENO, C.F.; SANTANA, J.R.F. de. Propagação in vitro de Erythrina velutina. Ciência Rural, v.40, p.1090-1096, 2010.

COUTO, M.; WAGNER JÚNIOR, A.; QUEZADA, A.C. Enraizamento in vitro do porta-enxerto de Prunus sp. 'Barrier' em diferentes concentrações de ácido indol-3-butírico (AIB) e do meio Murashige e Skoog (MS). Revista Brasileira de Agrociência, v.9, p.367-370, 2003.

DISARZ, R.; CORDER, M.P.M. Multiplicação de gemas axilares de Acacia mearnsii de Wild. sob diferentes meios de cultura. Revista Árvore, v.33, p.599-606, 2009.

DUTRA, L.F.; WENDLING, I.; BRONDANI, G.E. A micropropagação de eucalipto. Pesquisa Florestal Brasileira, n.58, p.49-59, 2009.

GOMES, G.A.C.; PAIVA, R.; HERRERA, R.C.; PAIVA, P.D. de O. Micropropagation of Maclura tinctoria L.: an endangered wood species. Revista Árvore, v.34, p.25-30, 2010.

GRATTAPAGLIA, D.; MACHADO, M.A. Micropropagação. In: TORRES, A.C.; CALDAS, L.S.; BUSO, J.A. (Ed.). Cultura de tecidos e transformação genética de plantas. Brasília: Embrapa-SPI; Embrapa-CNPH, 1999. v.2, p.533-568.

HAMANN, A. Adventitious root formation of loblolly pine (Pinus taeda L.): developmental sequence and effects of maturation. Trees, v.12, p.175-180, 1998.

LLOYD, G.; MCCOWN, B. Commercially-feasible micropropagation of mountain laurel, Kalmia latifolia, by use 
of shoot tip culture. International Plant Propagation Society Proceedings, v.30, p.421-427, 1981.

LUCAS,M.A.K.;FAGUNDES,J.D.;PEREIRA,D.D.; SARMENTO. M.B. Micropropagação de violeta-africana (Saintpaulia ionantha Wendl.): efeito da benzilaminopurina na multiplicação. Ciência e Agrotecnologia, v.31, p.1380-1385, 2007.

MURASHIGE, T.; SKOOG, F. A revised medium for rapid growth and bioassays with tobacco tissue cultures. Physiologia Plantarum, v.15, p.473-497, 1962.

NICIOLI, P.M.; PAIVA, R.; NOGUEIRA, R.C.; SANTANA, J.R.F. de; SILVA, L.C.; SILVA, D.C. da; PORTO, J.M.P. Ajuste do processo de micropropagação de barbatimão. Ciência Rural, v.38, p.685-689, 2008.

RIBAS, L.L.F.; ZANETTE, F.; KULCHETSCKI, L.; GUERRA, M.P. Micropropagação de Aspidosperma polyneuron (peroba-rosa) a partir de segmentos nodais de mudas juvenis. Revista Árvore, v.29, p.517-524, 2005.

ROCHA, S.C. da; QUORIM, M.; RIBAS, L.L.F.; KOEHLER, H.S. Micropropagação de Cabralea canjerana. Revista Árvore, v.31, p.43-50, 2007.

ROGALSKI, M.; GUERRA, M.P.; SILVA, A.L. da. Multiplicação in vitro da ameixeira 'Santa Rosa': efeito da citocinina BAP. Revista Brasileira de Fruticultura, v.25, p.365-367, 2003.

STATSOFT. Statistica: data analysis software system. Version 10. 2010. Available at: <www.statsoft.com>. Accessed on: 10 Jan. 2011.

XAVIER, A.; SANTOS, G.A. dos; OLIVEIRA, M.L. de. Enraizamento de miniestaca caulinar e foliar na propagação vegetativa de cedro-rosa (Cedrela fissilis Vell.). Revista Árvore, v.27, p.351-356, 2003.

Recebido em 29 de junho de 2012 e aprovado em 4 de dezembro de 2012 